\title{
Construction of "Five-in-One" Academic Planning Guidance System Between Chinese and Abroad
}

\author{
Ke Ma, Chao Dong*, Jilong Zhang, Zihang Zhao \\ School of International Education, Nanjing Institute of Technology, P.R. China \\ *Corresponding author. E-mail: knjy@njit.edu.cn
}

\begin{abstract}
Academic planning is an emerging topic in recent years. At present, many universities 'academic planning system is not perfect, the construction of teachers is not complete, the students' cognition and positioning of their own situation are not accurate, and the awareness and ability of academic planning is weak. Through the construction of "five-in-one" student planning guidance system, implement different programs for different students, help students find problems and solve problems, effectively improve students ' learning autonomy and employment competitiveness, let college students graduate smoothly and work successfully, and then ensure the quality of college talent training and improve the level of higher education.
\end{abstract}

Keywords: Academic Planning Guidance, Teaching Management, Talent Training Quality.

With the reform of national political and economic system, the employment policy changes accordingly. From "unified package unified distribution" to "supply and demand meet, two-way choice" to "market-oriented independent choice of employment", many college students are facing the current situation of graduation and unemployment. Academic planning and guidance are important parts of talent training and play a pivotal role in their academic planning and employment guidance. However, many universities have not established a perfect guidance system, and this paper plans to put forward a relatively perfect guidance system based on the current situation of universities at home and abroad.

\section{INTRODUCTION OF COLLEGE ACADEMIC PLANNING AND GUIDANCE INSTITUTION}

In many universities at home and abroad, there are specialized college student academic planning guidance centers, the main responsibility is to guide students to master the correct learning methods, develop independent learning ability, promote comprehensive support activities, including holding full academic and success lectures, reports, exchange meetings, and peer academic exchanges, and for individual students, develop support plans, formulate help methods, process and personalized management, to help students out of learning difficulties. The Academic Planning Center is generally affiliated to the Academic Affairs Office, and the Student Academic Guidance Center consists of academic guidance experts, full-time staff, and student academic tutoring volunteers. For example, the Student Academic Guidance Center of China University of Science and Technology currently has 47 staff, and 29 staff at the University of Georgia. Dozens, or even dozens of student assistants will also be hired to work.

\section{THE CURRENT SITUATION OF ACADEMIC PLANNING AND GUIDANCE FOR COLLEGE STUDENTS}

\subsection{Current Status of Colleges And Universities}

Academic planning, only a new concept put forward in recent years. abroad, universities in the US began earlier in students ' academic planning and development. Take the United States as an example, according to the 2011 National Survey of the American Academic Guidance Association, about 71 percent of universities across the country have set up institutions responsible for students ' academic planning guidance. It is not difficult to see that the construction of American universities in students ' academic planning and guidance has begun to take shape. Representative by the University of California, Berkeley and Stanford University in the American Ivy League, it is able to fully use the role of the center to promote all-round student development. 
However, in China, academic planning theory was founded by Mr. Zhang Hengliang, an expert in academic planning and college decision-making. It inherited and developed the career guidance and career education theory that originated in the United States from the last century. In recent years, the academic planning guidance of Chinese colleges and universities has increased. According to the literature, at present, China has also established the corresponding theoretical system of learning and development of college students. However, according to incomplete statistics, only 32 universities in the country have set up college student development centers, including 24 ministerial universities. It can be seen that China's development planning center is centrally established in key universities, and [2] has not been fully implemented in China.

\subsection{Student Status Quo}

In terms of academic planning, there are many problems at the student level. According to the questionnaire, 61.9 percent of the students had made academic plans based on their own conditions, while about 38.1 percent never did so. In different periods, about $35.4 \%$ of the academic planning, about $39.3 \%$ of the sophomore, about $17.5 \%$ of the junior, and about $7.8 \%$ of the senior year. [3] shows that students do not take the initiative of making academic planning. In addition, the survey found that $39.6 \%$ of students think "understand their own characteristics and advantages", $6.9 \%$ think they "understand their employment prospects and employment field", $21.5 \%$ think they "keen to professional trends and can take it as a reference factor for their academic planning" [3], you can see that students are not very understanding about their situation, to a certain extent lack the ability to make academic planning. Although some students made academic plans, when asked if they could persist, $10.8 \%$ chose to "stick," $66.4 \%$ "for a while," and $22.8 \%$ chose to have "a short time" [3]. This suggests that students still lack the ability to implement their academic planning or a lack of selfcontrol.

\section{THE IMPORTANCE OF COLLEGE ACADEMIC PLANNING GUIDANCE}

\subsection{Development Perspective of Students}

\subsubsection{Changes Education Patterns and Improves Learning Autonomy}

Influenced by China's national conditions and longterm life model, Chinese students receive a nonindependent indoctrination education since childhood. Students follow the teacher's rhythm; the teacher instilling the ready-made knowledge conclusions into the students and subjectively determines the teaching process. Over the long term, a dependence on learning has been formed. However, universities are different from junior high schools and high schools. Without teachers ' forced restraint of learning, teachers only play a role in guiding and providing assistance. As a result, many students hold a "long live 60 points" attitude, and even cannot graduate successfully phenomenon also emerge in an endless stream. Therefore, in this case, students need to strengthen self-management, and reasonable learning planning will play a vital role.

\subsubsection{Adapts To College Life and Sets Early Goals}

University is often called as a small society, and it is also the most effective place to improve a person's comprehensive quality. However, many college students enter college, as if they get freedom. Many college students feel confused after entering college, and do not have a clear concept of their major or the future. Over time, the lazy life has become a daily portrayal of most college students. In my opinion, the root cause of laziness is no goal. In high school, we also stare at our goals and inspire ourselves every day. After entering the relatively relaxed life of college students, it is common to stay up late on the Internet, sleep in classes and take exams. According to the survey, $63 \%$ of young students stay up late almost every day, with entertaining $44 \%$. Over $85.8 \%$ of young students will stay up late 3 or more times in 5 days. [4] guides students to set early goals and make good academic plans,

\subsubsection{Expertise Improvement To Overcome Psychological Barriers}

With the development of economic globalization, higher education gradually globalization. In recent years, many colleges and universities have opened the teaching mode under Chinese-foreign cooperation in running schools. Chinese-foreign cooperation is mainly to introduce high-quality educational resources, realize cultural integration and expand their vision through different exchanges. However, the teaching quality of many universities ' Chinese-foreign cooperation in running schools is not well reflected. Cultural differences and language barriers have put students under greater pressure. They do not understand the basic situation of the major, employment prospects and the needs of the society; lack of understanding of the training program, not clear how to carry out course selection and study; and many doubts about postgraduate study, work and decision abroad, which affect the students ' knowledge and ability training. In such cases, the academic planning guidance center is even more important. Through the planning center, communicate with student heart and heart, introduce relevant professional knowledge, overcome students ' psychological obstacles, and develop a practical learning plan. 


\subsection{Perspective Of Social Development}

Since China promoted the reform of the higher education system in the actual 1980 s, China's higher education has made great achievements. According to statistics, by the end of 2014, there were 2,824 universities in China, ranking second in the world and a total education of 35.59 million, ranking the first [5] in the world. However, since 1999, China's higher education has greatly expanded year after year, increasing sharply in number. However, the quality of teaching is ignored and leads to the chaotic structure of related industries, among which the most prominent problem is the low talent training ability of colleges and universities. According to the literature, the current dilemma of talent training mode in colleges and universities is mainly manifested in the following four aspects: the lag of talent training concept, the convergence of talent training target, the unity of talent training target and the imperfection [9] of the talent training system. The lack of the performance of academic planning is also the imperfect training system, establish a complete academic planning guidance center, improve the university management system, improve the management efficiency and the quality of talent training, respond to the call of the national education reform, and then improve the employment rate and employment quality of colleges and universities, and transmit more high-quality talents for the society.

\section{STRATEGY OF ACADEMIC PLANNING GUIDANCE SYSTEM FOR COLLEGE STUDENTS}

\subsection{Principles Of "Five-in-One" Academic Planning Guidance System}

\subsubsection{Student Development Theory}

Student development theory is based on the traditional British system of "alternative parenting" and "student personnel service". In the late 1960 s and early 1970 s, student development theory emerged into continuous development. Student development theory is the application and development of human development theory in the field of higher education, it is a comprehensive theory, which mainly includes [8] such as the theory of psychological development theory, cognitive structure theory, type theory, human and environmental interaction theory and SLI (students ' theory of learning). In the process of planning, according to the college student development theory, college student development concept, college student affairs from academic affairs, student career plans are formulated from different angles.

\subsection{2. "Student-Centered" Education Theory}

School student management department in the process of student academic planning guidance, its work concept gradually transformed from mandatory management to service management, from the needs of students to guide it to formulate reasonable academic planning, fully reflects student management guidance and service, which is conducive to eliminate students ' resistance, stimulate its autonomy as learning subjects, if students can clearly plan four years of study life, and reasonable implement, then undergraduate academic quality and talent training quality will have the most basic guarantee.

\subsubsection{Dynamic Development Theory}

The principle of dynamic development means that the academic planning of college students is a dynamic development process, with different requirements at different stages, and reasonable adjustments should be made in time based on the development of college students and changes in the external environment. The ability and consciousness of college students' academic planning are not developed in a day. Instead, the school needs to accurately grasp the students thinking dynamics, learning ability, self-recognition, and selfdevelopment goals based on the social and economic development trends and the latest needs of the society for talents. Based on the dynamic monitoring mechanism of academic planning, students are guided in a targeted manner to achieve the optimization of academic planning.

In the process of implementation, the Academic Planning Center establishes a staged evaluation and feedback system, develops a dynamic academic planning monitoring and early warning mechanism, and continuously adjusts the planning according to the development of students and changes in the external environment to ensure the scientific and professional academic planning. At the same time, students often conduct self-examinations and adjust their plans for the next stage according to their own development. At the same time, close home-school ties, pay attention to teacher-student interaction, and give full play to homeschool education. Combining the three of "studentschool-parent" organically, gather the positive energy of teachers and students, realize the dynamic and healthy operation of college students' academic planning, and continuously improve the quality and efficiency of academic planning.

\subsubsection{Active Guidance Theory}

At present, the post-2000 college students have become the main force of college students. Most of the post-2000 college students are the only child, with 
distinctive personality and unique opinions on new things. However, their cognition and positioning ability are poor, especially for some college students, their awareness of academic planning is vague, and their ability of academic planning is insufficient. Therefore, colleges and universities must strengthen the active guidance of college students' academic planning, and act as a good guide for the high-quality development of college students.

The school insists on the combination of internal intervention and external guidance to improve the working art of active guidance. On the one hand, the school set up specialized college students' academic work, improve the relevant rules and regulations, establish a by professional teachers, counselors, psychologists, and peer guidance of college students' academic work specialization, long-term planning, pay attention to in the process of construction of initiative, to put forward Suggestions on the construction of academic planning system. To protect the healthy growth of college students. On the other hand, an interactive platform should be built to actively intervene in college students' academic planning, grasp the specific process of college students' academic planning through new media, regular teacher-student interaction, peer interaction and other ways, and provide timely guidance from the outside. At the same time, through the academic planning guidance competition, excellent alumni report and other forms, guide college students to make academic planning to improve their academic planning quality, so as to achieve the best effect of career planning.

\subsubsection{System Theory}

The core idea of the system theory is the overall concept of the system. Betalangi stressed that any system is an organic whole, it is not a mechanical combination or simple addition of the various parts, and the overall work function of the system is a new quality that the elements are not available in isolation. Barnard believes that the organization is a cooperative system. The organization is not a rigid structure composed only of the division of responsibilities and the power structure. The organization is a system of activities and forces coordinated with human consciousness. Professional groups as an organization is a formal organization of teachers in different professions. From part-time teachers, famous teachers, lecturers to professors, different types of teachers have different experience, abilities and characteristics. The essence of the organization and cooperation system requires the cooperation of complex members within the professional group, so that "coordinated activities" can become the "power" system, more scientific and professional to formulate academic planning for students and improve the feasibility of academic planning [9].

\subsection{Specific Measures}

\subsubsection{Formulate The Academic Planning System "With Institutions As The Carrier"}

Establish a complete academic planning and guidance center for college students. At the college level, by professional teachers, counselors, head teachers, psychological counselors formed a professional team, through a comprehensive understanding of student character characteristics, ability and future social needs, determine the goal of university learning stage, determine academic route, and then combine the actual situation of students, to ensure the quality and necessary to obtain stage goal ability, so as to maximize the development of students life career development efficiency, and achieve personal sustainable development. The "Academic Planning and Guidance Center" of the School of International Education of Nanjing Institute of Engineering is a student service platform based on the concept of "student-centered education". Center according to the needs of students 'learning and life and the characteristics of physical and mental development, such as learning life adaptability, learning method guidance, professional ability improvement, psychological pressure debugging, interpersonal communication, career planning affect students' learning and development problems, from freshmen, to the learning process, to graduation employment for purposeful, planned, step-by-step guidance and service. The center adopts the appointment system service, and forms a team with ideological and political counsellors, professional teachers, language teachers, retired old teachers and excellent student backbone as the core. Ideological and political counsellors provide thoughtful and comprehensive guidance services at the ideological level, and guide students to establish a correct outlook on life, values and concept of growth. The teacher tutoring group formed by professional teachers, language teachers and retired old teachers and the student mutual aid group set up by student backbone conduct targeted mutual learning, stimulate students ' internal learning motivation, improve the enthusiasm and initiative of learning, and help students plan the university learning and future development direction.

\subsubsection{Enrich The Academic Planning System By "Taking Activities As The Carrier"}

Activities should be conducted based on the principle of "teaching students according to their aptitude", according to the theoretical support of "five in one" and carry out different activities for different types of students. For some introverted students who are not good at communication and have a relatively weak foundation, they can hold "teachers and students" meeting and "peers" sharing activities. "Teachers and students" meeting and "peers" sharing meeting, are a process of 
communication. The process of teaching is the process of interaction between teachers and students. Both teachers and students understand each other, find out the problems, and find the appropriate ways to solve the problem in the effective communication. In addition, the "teacher and student" meeting can also be known as a communication and feedback mechanism. The students regularly talk and summarize with the teachers, as well as the periodic exploration of learning methods, strengthen academic exchanges and establish a good relationship between teacher and student. In this process, to create a relatively relaxed learning atmosphere, to improve the students ' enthusiasm for learning. Pender tutoring originated in the United States, and in the $1960 \mathrm{~s}$ it created a non-professional movement for mutual assistance between students and students. Gray and Tingdor proposed the concept of "peer counselling". They define it as " taken by nonprofessional's as helpers. peer sharing tutoring usually occurs between peers. They live in the same environment, have the same age and have similarities in their cognition of external things. They can reach agreement and communicate more effectively, so as to achieve twice the result with half the effort. This activity not only cares for the withdrawn hearts of depressed students, but also exercises their ability to communicate with others. Students with strong ability, unique views on things, and more active thinking can improve them by holding career planning competitions. Career competition can popularize college students ' career planning knowledge and spread the concept of career growth. On the basis of academic planning, I connect with career planning, understand my own strengths and weaknesses, interests and ability values, and then based on my own decision-making, determine recent goals and long-term goals, formulate specific action plans to improve college students ' innovation ability, practical ability and employment and entrepreneurship ability. In addition, at the secondary college level, hold regular theme lectures, including study abroad consultation seminar, study planning and application lectures, postgraduate entrance examination lectures, academic specification lectures and college students career planning lectures and other academic lectures, according to the current social situation, let students recognize themselves, correct positioning, understand how college students improve their competitiveness, give them a clear future plan for the future. For Chinese-foreign cooperatively-run schools, Take the Nanjing Institute of Engineering School of International Education as an example, With " two construction, One cooperation " as the carrier, Adhere to the combination of academic planning guidance with "construction of brand culture, construction of fine style of study, and Chinese-foreign cooperation in running schools", Based on the brand culture construction, Constantly enrich the content of academic planning, Create a good atmosphere, Encourage students enthusiasm for academic planning, Push the cultural construction to a higher cultural realm foundation; With the construction of excellent style of study as the starting point, Enhance the cohesion of the class and the college, Realize the organic combination of "Personal-ClassCollege", Make full use of the college resources, Improve the academic planning advantages; With Chinese-foreign cooperation in running schools as an improvement, Strive to explore new models of education and teaching, internationalize and globalize our horizons, continuously improve the quality of personnel training, and deepen the connotation of academic planning.

Figure 1. Guidance Concept System of College Academic Planning.

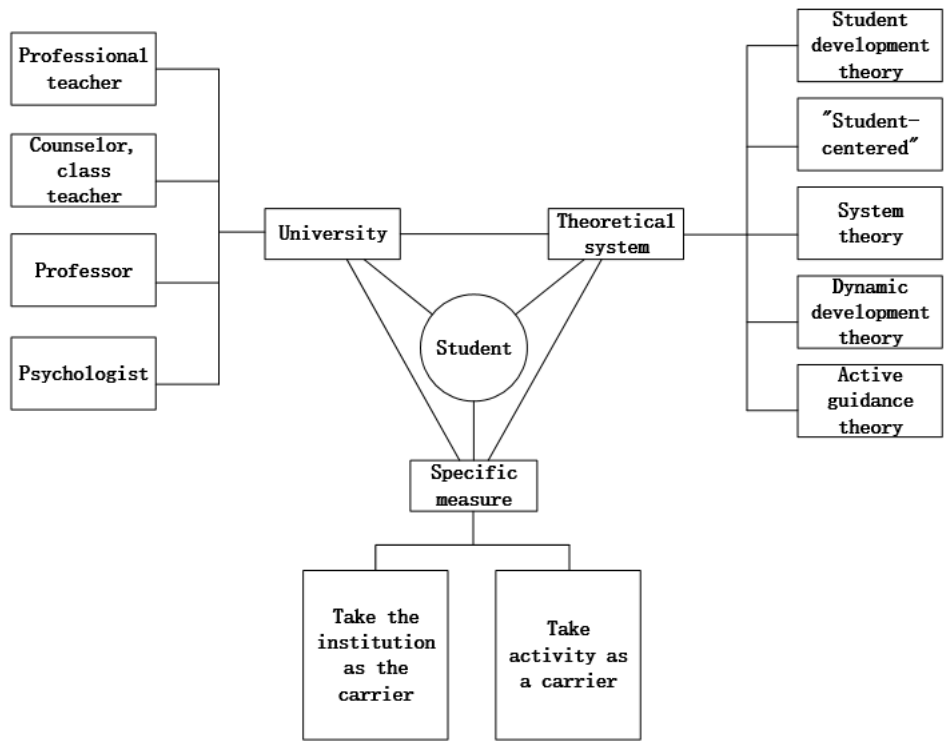




\section{CONCLUSION}

Academic planning and guidance are still emerging topics in China. Through the analysis of the whole university, it shows that the academic planning guidance institution of domestic universities is not perfect, including the construction and implementation of the school and student level. Through the support of the "Five-in-one" theory, put into corresponding practice, it can help schools become more professional and scientific in the process of improving the academic planning guidance system, students have more accurate positioning and the formulation of academic planning more feasible.

The construction of college students 'academic planning guidance system is a complex process, in this process needs the joint efforts of schools, colleges, teachers, parents, students, promote the academic planning guidance smoothly, guide students' scientific planning, and realize all-round development, constantly stimulate students to grow up, and cultivate more practical talents for the society.

\section{AUTHORS' CONTRIBUTIONS}

Ke Ma, Chao Dong, Jilong Zhang, Zihang Zhao designed research, performed research, analysed recent data and wrote the paper.

\section{ACKNOWLEDGMENTS}

This research was financially supported by the Philosophy and Social Sciences Research Project in Universities of Jiangsu Province (No: 2020SJB0153).

\section{REFERENCES}

[1] H. Yue, W. Tian, T. Wang, Comparative Research and Enlightenment on the Construction of Some College Students ' Learning and Development Center in China and America, Journal of Hebei Agricultural University (Agriculture and Forestry Education Edition), 18 (05) 2016

[2] J. Hao, C. Wang, Thinking and Exploration of Buil ding Academic Planning Guidance System for Coll ege Students

[3] J. Ai, B. Zhang, W. Huang, M. Zou, Z. Lv, Y. Huan g, Young Students stay up late with mobile phone a ddiction, time management, Hebei Youth Managem ent Cadre Academy, 33 (02) 2021

[4] Education Third Party Assessment of Higher Education [EB/OL]. 2018-10-12.
[5] L. Li, A Change in the Popular Development Mode of Higher Education in China, Education Research of Tsinghua University. 35 (01) 2014

[6] Y. Yao, Difficulties and Beyond of College Talent Training Model: Based on the perspective of adaptability, Shandong Higher Education 7 (05) 2019 56-62.

[7] C. Ma, 20th Century American University Student Affairs Studies Nanjing Normal University, 2007.

[8] S. Yang, Y. Han, Teacher Cooperation of Higher Vocational Colleges in Social System Theory, Journal of Northwest Adult Education College (03) 2021 83-87.

[9] Y. Hu, Application of peer Psychology in Adaptive Education for College Freshmen [J], Law and Society, (17) 2012 232-238. 